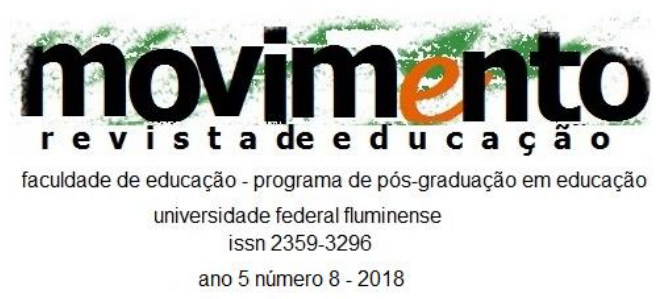

\title{
POLÍTICAS CURRICULARES NO ESTADO DO RIO DE JANEIRO O Discurso do Sujeito Coletivo dos Professores de Ciências
}

\author{
Diego Mota \\ Colégio Pedro II, \\ Rio de Janeiro, RJ, Brasil \\ Denise Rocha Correa Lannes \\ Universidade Federal do Rio de Janeiro, \\ Rio de Janeiro, RJ, Brasil
}

\begin{abstract}
Resumo
O ensaio aborda a política curricular da rede estadual de educação do Rio de Janeiro. A pesquisa possui como questão central conhecer as concepções dos professores de Ciências acerca do Currículo Mínimo (CM) dessa disciplina. Esta análise, aportada na Teoria das Representações Sociais e no Discurso do Sujeito Coletivo, busca explorar os elementos centrais no discurso de 15 docentes sobre do currículo. Os resultados mostram a necessidade de ajustes na implantação do currículo para aproximar os docentes do Currículo Mínimo, o qual propõe desenvolver competências na sala de aula. Palavras chave: currículo escolar; políticas educacionais; professores.
\end{abstract}

\section{EDUCATIONAL POLICIES IN RIO DE JANEIRO The Curriculo Mínimo Through Science Teachers' Discourse}

\begin{abstract}
This research approaches the curricular policy adopted in public schools in Rio de Janeiro, focusing on Curriculo Mínimo de Ciências. The proposal, mandatory, is structured via abilities and competencies. The proposal Its introduction in the educational process is accompanied by institutional pressures: assessments, awards and accountability. In this essay, the interviews of 15 science teachers were gathered in a Collective Subject Discourse. The results point out the need for adjustments in curriculum implementation to bring teachers closer to the proposal.

Key words: school curriculum; educational policies; teachers.
\end{abstract}




\title{
movimento \\ faculdade de educação - programa de pós-graduação em educação universidade federal fluminense \\ issn 2359-3296 \\ ano 5 número 8 - 2018
}

\section{UNA POLÍTICA CURRICULAR FLUMINENSE A Través del Discurso de los Profesores de Ciencias}

\begin{abstract}
Resumen
Este ensayo se centra en la política curricular adoptada por la red de educación del estado de Río de Janeiro, centrándose en Currículum Mínimo de Ciencias. La propuesta, de carácter obligatorio, se basa en las competencias. Su implementación es fomentada por una evaluación a gran escala asociada y el bono de las escuelas. En el estudio, entrevistas sobre el programa de estudios, hecho con 15 profesores de Ciencias, han sido reunidas como discurso del sujeto colectivo. Los resultados muestran la necesidad de ajustes en la implementación del currículo, para acercar los docentes a la propuesta.

Palabras clave: curriculum escolar; políticas educativos; maestros.
\end{abstract}

\section{Introdução}

A preocupação com os dados revelados pelos indicadores de qualidade impulsionou mudanças nas políticas públicas educacionais do Brasil nas últimas duas décadas (BROOKE et.al.; 2011; BARRETO, 2013). A influência de organizações internacionais, como a Organização das Nações Unidas para a Educação e o Banco Mudial, foi determinante. Diversos países assumiram compromissos políticos para melhorias na qualidade da educação básica (LIBANEO, 2012).

Esse movimento gerou uma onda de reformas intimamente relacionadas entre si, cujas estruturações possuem um arranjo semelhante (BALL, 2002). Uma engenharia que integra políticas de responsabilização, de centralização de currículo e de criação de sistemas de avaliação em larga escala (SEGATTO, ABRUCIO; 2017). Como consequência, muitos estados e municípios também reorganizaram suas redes. Desenhou-se "um robusto e eficiente sistema de avaliação em todos os níveis e modalidades de ensino" (GUIMARÃES, 2009, p. 273). Tudo isso para melhorar os indicadores educacionais. 


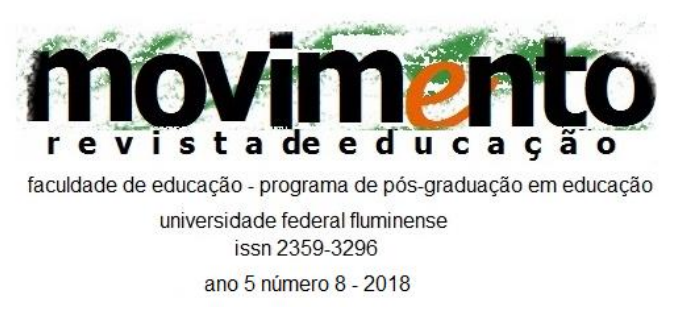

O Rio de Janeiro foi um desses estados. Em 2008, com a mudança de governo, o extinto Programa Nova Escola foi substituído pelo Sistema de Avaliação da Educação Básica do Estado do Rio de Janeiro (SAERJ). Uma das principais metas estabelecidas foi "estar entre as cinco primeiras posições no ranking de educação nacional até 2014" (RIO DE JANEIRO, 2011 b). O "foco nos resultados" tornou-se a política oficial da educação.

Entretanto, essa iniciativa não chegou às escolas como um caminho opcional para os docentes e para os alunos. Foi uma proposta obrigatória para toda a rede, na forma de um projeto que objetivava melhorar a educação pública estadual. No fim da década de 2000, os İndices de Desenvolvimento da Educação Básica (IDEB) alocavam o estado do Rio de Janeiro entre os mais baixos do país na qualidade do ensino (BRASIL, 2010).

Nesse contexto, desenvolveu-se o presente estudo. Este artigo tem como proposta central discutir a política curricular através do discurso do sujeito coletivo dos professores de Ciências acerca do Currículo Mínimo da rede estadual de ensino do Rio de Janeiro. Estudos que abordam os significados de um elemento pertinente em um grupo social, especialmente nas políticas públicas, são de fundamental relevância. Seus resultados, somados a outros estudos, trazem informações que podem contribuir para repensar 0 direcionamento dessas políticas em busca de afirmações ou de correções (JODELET, 2001; MAZZOTI; 2008).

Além desta introdução, este texto se estrutura em mais cinco seções. A primeira retrata a política educacional adotada pelo estado do Rio de Janeiro, o papel dos currículos nessas reformas educacionais, além de caracterizar o Currículo Mínimo de Ciências. A segunda apresenta a Teoria das Representações Sociais e o Discurso do Sujeito Coletivo, que ancoram as metodologias adotadas neste estudo. A seção seguinte descreve os procedimentos metodológicos da 


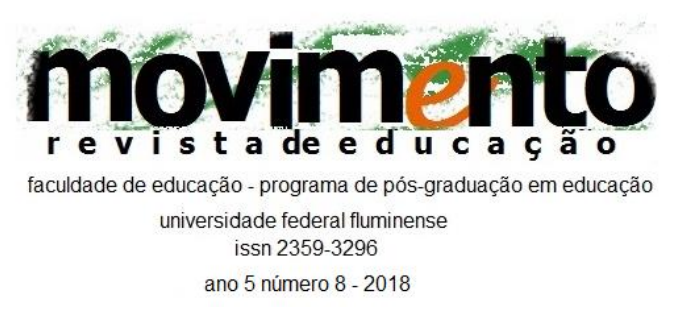

pesquisa. A quarta parte traz os resultados e discute as ideias centrais das representações sociais discursivas dos professores. Nas conclusões, são feitas considerações acerca dos resultados e sua relevância para a discussão da política curricular.

\section{A política curricular}

No processo de reestruturação de sua rede, a Secretaria de Estado de Educação do Rio de Janeiro (SEEDUC) criou o Sistema de Avaliação da Educação Básica do Estado do Rio de Janeiro (SAERJ) em 2008. Um programa centrado no gerenciamento da gestão escolar, na busca de melhorias dos indicadores de eficiência taxa de reprovação, evasão escolar e distorção série/idade, nas avaliações anuais em larga escala e na bonificação dos servidores (CERDEIRA, ALMEIDA, 2013).

O seu arcabouço foi elaborado em consonância com outras avaliações em larga escala, como a Prova Brasil e o Programa Internacional de Avaliação de Estudantes (RIO DE JANEIRO, 2011a). Além disso, o SAERJ foi apenas parte das estratégias de investimento propostas pela Secretaria de Educação. A modernização pela informatização da rede e de seus sistemas de comunicação, assim como o treinamento dos gestores e dos professores, também foram vias adotadas pela SEEDUC na implantação desse projeto. Também foi estabelecido um pacote com planos e metas a serem desenvolvidos nas escolas. Melhorar os indicadores educacionais por uma política de incentivos e de bonificação era o lema trazido pela SEEDUC (RIO DE JANEIRO, 2011 b).

Uma das chaves principais para chegar a esse objetivo foi a adoção de um Currículo Mínimo (CM) obrigatório em sua rede. Esse currículo contemplou todas as disciplinas da rede estadual pública de ensino gradualmente. Em 2010, a 


\section{movimento \\ faculdade de educação - programa de pós-graduação em educação universidade federal fluminense \\ issn 2359-3296 \\ ano 5 número 8 - 2018}

SEEDUC anunciou aos professores, através de seus canais de comunicação, seu projeto de construir uma matriz curricular baseada em habilidades e competências.

Nesse cenário, entre 2009 e 2014, a educação pública estadual saiu da penúltima posição, entre as redes estaduais, para a quarta mais bem avaliada do país, segundo o Índice de Desenvolvimento da Educação Básica (IDEB) para o ensino médio (BRASIL, 2014). Entretanto, alguns autores analisam esses resultados com ressalvas (TEIXEIRA, 2015; CHIRINÉA, BRANDÃO; 2015). Eles chamam a atenção quanto à aproximação feita entre os conceitos de qualidade e de quantidade em educação, quando consideramos os indicadores educacionais apenas como números.

Observa-se a consolidação de mecanismos de monitoramento e design empresariais e gerenciais nesses programas governamentais. $\mathrm{Na}$ visão de Sousa (2014), as estratégias adotadas para alcançar bons resultados nas avaliações em larga escala podem fornecer concepções distorcidas de uma educação de qualidade. Diante dessas ponderações, também se faz necessário investigar o papel do currículo no escopo dessas políticas educacionais.

\section{Currículo: 0 coração da política}

Na implantação de um projeto educacional, o currículo tem sido um elemento de fundamental relevância, no sentido de ser "o centro gravitador de toda prática pedagógica" (SACRISTAN; 2000; p. 32). Segundo o Banco Interamericano de Desenvolvimento, "nenhuma política ou reforma nessa área pode ter sucesso se não colocá-lo no centro", ele é "o coração de um empreendimento educacional" (LOPES, 2004, p.110). 


\section{movimento \\ faculdade de educação - programa de pós-graduação em educação universidade federal fluminense \\ issn 2359-3296 \\ ano 5 número 8 - 2018}

A implantação de um currículo básico nos sistemas educativos é uma maneira de o estado organizar sua gestão e direcionar seus objetivos políticos. Essa forma de regulação é "consequente da própria estrutura do sistema educativo e da função social que cumpre" (SACRISTAN, 2000, p.108). Essas ações são relevantes em realidades como a brasileira, na qual existe a necessidade de se construir uma escolarização diferente do quadro atual, o qual tem como reflexos as desigualdades de formação e de oportunidades (RIBEIRO, 2013; FALVO, AMARAL, 2017).

Essa realidade, associada à imprescindibilidade da ação de políticas voltadas para melhorias na educação básica, há décadas, tem como condição indispensável para sua construção uma "ampla participação social da opinião pública" (JORGE, 1996, p.32). Essa colaboração é imperiosa para que as mudanças a serem construídas tenham menos resistências, sejam mais bem acomodadas e de fato efetivadas.

Nessa perspectiva, a implantação de um novo currículo, por sua centralidade nas políticas educacionais, tem como fundamento a participação concreta dos grupos diretamente envolvidos e da sociedade como um todo. Por esse motivo, descreveremos o enredo da elaboração do currículo adotado pela rede estadual pública de ensino do Rio de Janeiro.

\section{O Currículo Mínimo}

A SEEDUC apresentou a proposta curricular à sua rede em janeiro de 2011. Seu intuito era "promover uma expectativa comum sobre o que deve ser aprendido e ensinado em cada ano do ensino". Com isso "contemplar todos os conhecimentos importantes para que o aluno tenha uma formação completa". Nesse discurso, o estado objetivava "preparar os estudantes para o mundo do 


\section{movimento \\ faculdade de educação - programa de pós-graduação em educação universidade federal fluminense \\ issn 2359-3296 \\ ano 5 número 8 - 2018}

trabalho, para o estudo universitário e para a vida, estimulando a cidadania" (RIO DE JANEIRO, 2011').

Para a Secretaria de Educação, essa ação "não era uma questão de vontade, mas sim a necessidade de fazer a engrenagem funcionar de forma sincronizada" (RIO DE JANEIRO, 2011 d). Essa proposta curricular, baseada no conceito de 'padrão mínimo', em uma rede de ensino múltipla e complexa, pressupõe que a mesma "precisa ainda ser elaborada e preenchida em cada escola, por cada professor". Este definirá "aquilo que Ihe é específico, peculiar ou apropriado" (Rio de Janeiro $2011^{\mathrm{C}}$ ). O discurso destacado sugere a possibilidade dos professores criarem seus próprios planos curriculares. No entanto, enfatiza a obrigatoriedade do cumprimento da proposta definida como mínima.

No fim do primeiro ano dessa experiência, a SEEDUC revisou a estrutura do currículo da rede. Foram incluídas todas as disciplinas dos anos finais do Ensino Fundamental e Médio Regular da rede nesse modelo, inclusive as Ciências. Segundo a Secretaria, a concepção, a redação, a revisão e a consolidação desse documento foram conduzidas por equipes disciplinares de professores da rede estadual, coordenadas por especialistas em educação de universidades públicas do estado (RIO DE JANEIRO, 2011 ).

O convite aos professores para a participação da elaboração e da revisão foi feito e divulgado no site da SEEDUC na forma de chamada pública. Houve uma preocupação especial dos elaboradores do Currículo Mínimo em relação aos modelos para a lapidação de sua estrutura. Utilizaram as matrizes curriculares do Ministério da Educação, as avaliações internacionais de qualidade de ensino, a Prova Brasil e o Exame Nacional do Ensino Médio (RIO DE JANEIRO, 2011²).

Além desses referenciais, também foram considerados "vários artigos relacionados a reformas curriculares no Brasil e no mundo". Ainda, segundo a 


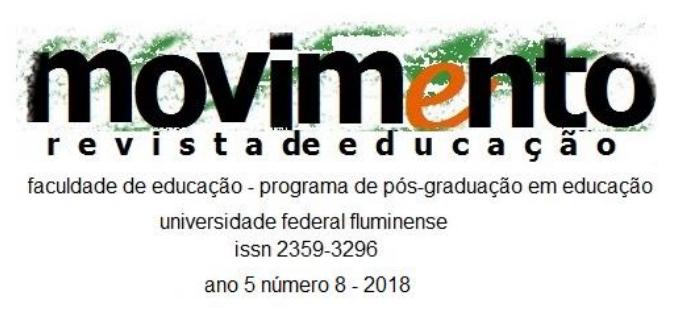

Secretaria, foram incorporadas as críticas e as sugestões dos professores da rede, recebidas através de sua página na internet e também em discussões presenciais (RIO DE JANEIRO, 2012).

O documento referente ao Currículo Mínimo de Ciências é descrito como "um conjunto seleto de conhecimentos essenciais". A estrutura pouco conteudista do CM é justificada em suas linhas como uma possibilidade dos docentes fazerem "escolhas mais adequadas à realidade de suas escolas" e terem autonomia didático-pedagógica em sua prática (RIO DE JANEIRO; 2012). Como exemplos dessa estruturação, apresentaremos as orientações para o primeiro bimestre do oitavo e do nono ano nas figuras 1 e 2.

Ao explorar o texto do CM de Ciências, encontra-se uma proposta de trabalho com verbos que sugere ações como pesquisar, elaborar, identificar, descrever, propor, definir, entre outros. Além disso, o cotidiano é colocado como objeto de análise e investigação. Os conteúdos são trabalhados através do desenvolvimento das habilidades e das competências, como também destacaram Cabral (2014) e Nascimento (2014).

Autores como Papert (2008) e Serres (2013) caracterizam a sociedade atual como detentora de livre acesso ao conhecimento através do mundo virtual e de suas redes. Segundo Hamilton (2002) e Canário (2009), esse atributo da contemporaneidade coloca em xeque nossa estrutura escolar baseada na transmissão de conhecimentos. Nessa conjuntura, as recentes propostas curriculares têm buscado alternativas à estrutura tradicional dos conteúdos (ASSMAN, 1999; REY, 2002; PERRENOUD, 2013). 


\section{movimento \\ faculdade de educação - programa de pós-graduação em educação universidade federal fluminense \\ issn 2359-3296 \\ ano 5 número 8 - 2018}

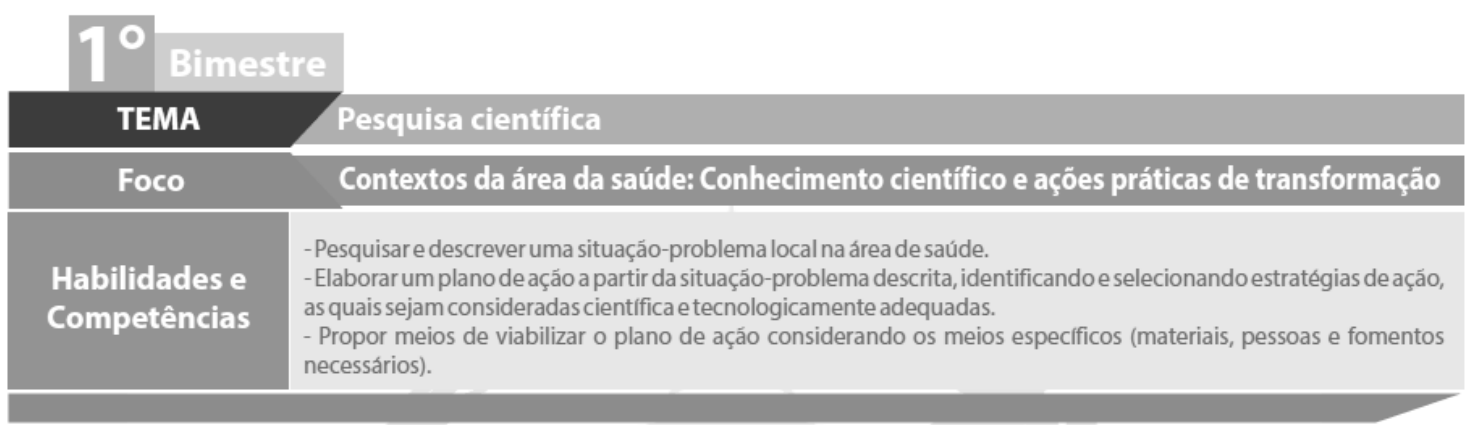

Figura 1: Currículo Mínimo de Ciências da rede estadual pública de ensino do Estado do Rio de Janeiro para o primeiro bimestre do oitavo ano (RIO DE JANEIRO, 2012, p.8).

\section{Ciências}

\section{$9^{\circ}$ ANO / ENSINO FUNDAMENTAL}

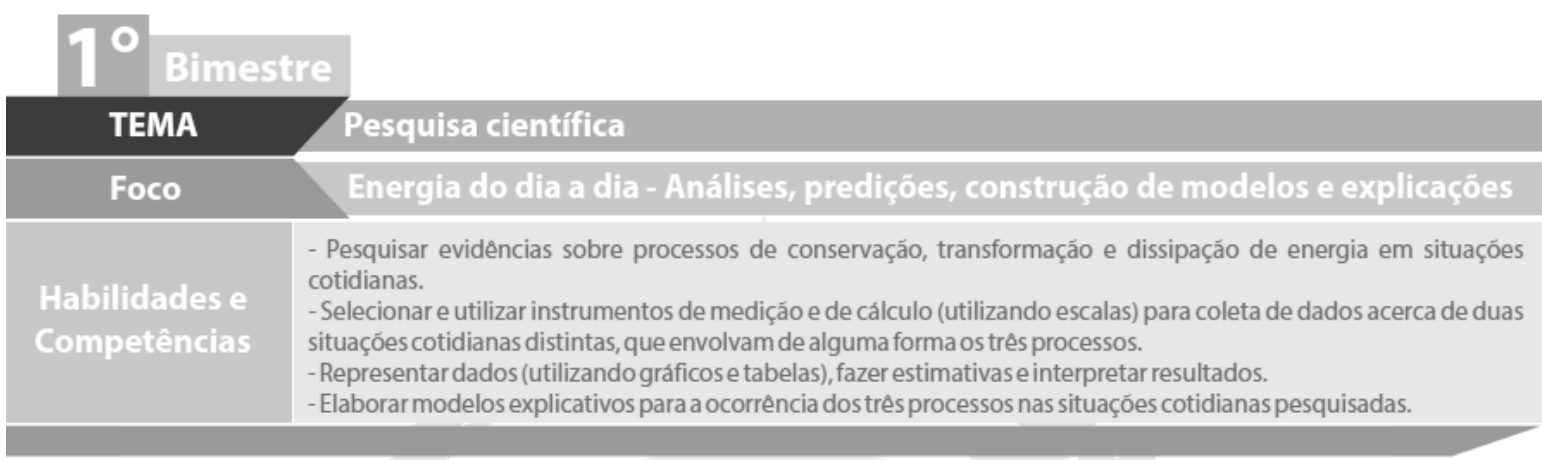

Figura 2: Currículo Mínimo de Ciências da rede estadual pública de ensino do Estado do Rio de Janeiro para o primeiro bimestre do nono ano (RIO DE JANEIRO, 2012, p.8).

Nesse espaço, os professores colocam o CM em ação e recriam-no nas suas especificidades. Nesse cenário, destacamos a possibilidade de discutirmos sobre um momento específico da profissão docente, no qual ocorrem interferências em suas práticas. Além disso, as demandas trazidas pelos estudantes e as propostas curriculares colocam os professores e a escola diante da necessidade de repensar seu papel. 


\section{movimento \\ faculdade de educação - programa de pós-graduação em educação universidade federal fluminense \\ issn 2359-3296 \\ ano 5 número 8 - 2018}

Por todos esses aspectos, conhecer a diversidade de posições dos docentes sobre um curriculo que busca desenvolver competências e habilidades na sala de aula se faz relevante. Nesse sentido, explorar as opiniões, as aprovações e os anseios manifestos na fala dos professores sobre o currículo adotado pode ser um caminho promissor para possíveis reflexões e ajustes nos rumos dessas políticas.

\section{Fundamentação metodológica: as Representações Sociais e o Discurso do Sujeito Coletivo}

A Teoria das Representações Sociais foi principiada pelo sociólogo francês Serge Moscovici no início dos anos 1960. Ela deu origem a um campo teórico que se constrói e se expande há mais de 50 anos. Sua proposta sugere que o conjunto de valores, convicções, práticas e costumes de um grupo tem o papel de normatizar o mundo e prescrever seu comportamento (MOSCOVICI 2009). As representações sociais (RS) são o senso comum. Esse conjunto de referenciais permite às coletividades operarem o seu funcionamento.

As representações sociais definem a identidade dos grupos sociais e, consequentemente, a sua diferenciação perante os demais. Orientam os comportamentos e as práticas sociais e também permitem justificar posturas e comportamentos (ABRIC, 2003). Ao acessar os significados das RS, é possível conhecer os nexos do alvo da investigação em um grupo social e acompanhar as modificações em suas relações e construções de mundo. Com isso, diante dos desafios que permeiam o cotidiano dos grupos sociais, podemos buscar ou sugerir soluções para os problemas e para os riscos em eventuais conflitos emergentes em sua temporalidade. 


\section{movimento \\ faculdade de educação - programa de pós-graduação em educação universidade federal fluminense \\ issn 2359-3296 \\ ano 5 número 8 - 2018}

O campo de estudo das RS oferece ferramentas que nos permitem acessar o conteúdo representacional de um objeto. Com isso, extrair de um grupo social elementos que ajudam a captar a organização, a acomodação e os significantes do objeto investigado na coletividade (JODELET, 2015).

\section{O Discurso do Sujeito Coletivo}

Nos anos 1990, Fernando Lefèvre e Ana Maria Lefèvre desenvolveram uma metodologia de pesquisa com base nas convergências dos discursos de um grupo social que investigavam. Essa metodologia reúne em uma única voz a manifestação de uma coletividade em relação ao tema Discurso do Sujeito Coletivo (DSC). Uma possibilidade que permite ao pesquisador tatear 0 significado da questão explorada no grupo investigado pela obtenção das opiniões através de questões abertas.

A técnica consiste em reunir, na forma de um discurso único redigido na primeira pessoa do singular, conteúdos de depoimentos com sentidos semelhantes, que busca produzir no leitor um efeito de "coletividade falando", dando lugar a um acréscimo de densidade semântica nas representações sociais, fazendo com que a ideia ou posicionamento dos depoentes apareça de modo "encorpado", desenvolvido, enriquecido, desdobrado (LEFÈVRE et al., 2009, pág. 2).

O DSC tem suas raízes ancoradas na teoria das Representações Sociais (RS) e, através de um sujeito plural, expõe "o regime natural de funcionamento das opiniões ou representações sociais" (LEFĖVRE E LEFĖVRE 2006, p. 3). Para Bourdieu (1994), a linguagem verbal é uma das faces do habitus, como um código comum de um grupo social. A linguagem expressa as posições aceitáveis dentro do grupo no qual os indivíduos estão inseridos.

Analisar as manifestações discursivas é uma possibilidade de captar as opiniões, as crenças, os valores e os desejos de um indivíduo ou de um grupo sobre um 


\section{movimento \\ faculdade de educação - programa de pós-graduação em educação universidade federal fluminense \\ issn 2359-3296 \\ ano 5 número 8 - 2018}

objeto que faz parte da sua vida cotidiana (LEFÈVRE; LEFÈVRE, 2014). Elas revelam os códigos socialmente compartilhados em um campo social, em seu caráter múltiplo, dinâmico, fragmentado e contraditório (FOUCAULT, 2004). Lefèvre e colaboradores (2009), considerando a complexidade das RS, defendem que o discurso é uma de suas camadas. Na visão dos autores, as Representações Sociais Discursivas ajudam na compreensão do senso comum e na busca de sugestões e de estratégias para os conflitos presentes nos grupos sociais.

São pesquisas cujo produto são representações sociais (...) que pode ser visto como um signo do tipo representa o pensamento ou opinião coletiva na medida em que busca trazer à luz não apenas o sentido ou significado de tal pensamento, mas também sua forma significante de depoimento, discurso, história (...) o DSC pode funcionar como "espelho psicanalítico" do pensamento de coletividades e grupos, o que faz dele instrumento útil para intervenções em que se busque despertar consciências coletivas e/ou ensejar diálogos com posturas ou opiniões distintas. (LEFÉVRE; LEFÉVRE; 2014; p.505).

O DSC é construído através da identificação das 'expressões-chave', 'ideias centrais' e 'ancoragens' no material verbal explorado. As primeiras são recortes do discurso que trazem conteúdo significativo. O seu teor é organizado em temáticas que representam as ideias centrais. As ancoragens são as certezas expressas pelo falante, afirmações presentes no texto que sustentam o discurso (LEFÈVRE; LEFÈVRE, 2006).

A construção do DSC se dá por uma sequência de procedimentos. Inicia-se com a soma das expressões-chave individuais que apresentam a mesma ideia central para depois fundi-las e convertê-las em um discurso cuja marca é a expressão de uma voz coletiva (Figura 3). 


\section{movimento \\ faculdade de educação - programa de pós-graduação em educação universidade federal fluminense \\ issn 2359-3296 \\ ano 5 número 8 - 2018}
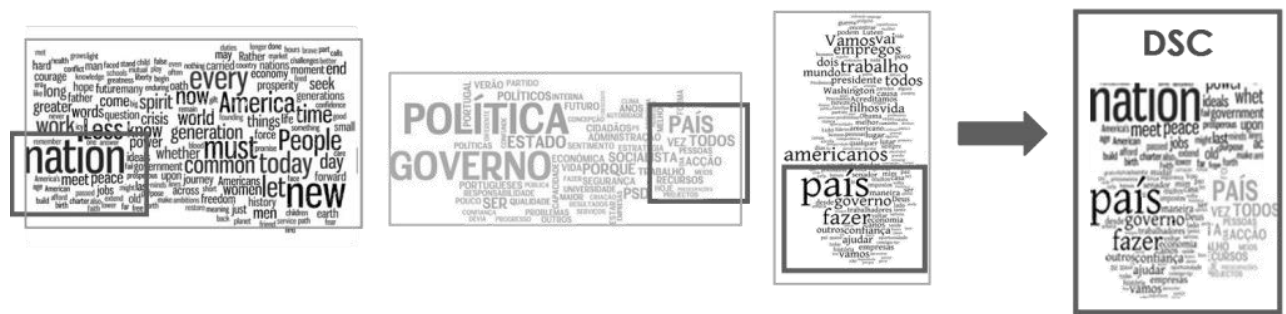

Figura 3: Discurso do Sujeito Coletivo (DSC): O pensamento de um grupo ou coletividade aparece como se fosse um discurso individual (VELLOSO; 2009).

Destacamos que a voz dessa coletividade manifesta como entidade coletiva é pontual para um grupo social com características singulares e distintas de outros grupos. Contudo, como consequência das transformações que ocorrem no contexto da sociedade em que está inserida, ela pode se modificar e se metamorfosear em outra fala, já que as representações sociais são dinâmicas (VALA, 1993, p.912).

As crenças e as concepções que circundam um grupo podem ser percebidas através de diversas expressões ou manifestações. Elas contribuem para a construção de uma realidade comum e também possibilitam a comunicação entre os pares de um meio, sua legitimação e sua distinção entre outros grupos sociais (JODELET, 1985; MOSCOVICI, 1988).

Considerando a complexidade das RS, Lefèvre e colaboradores (2009) situam as manifestações discursivas como uma de suas faces. Para eles, as Representações Sociais Discursivas podem contribuir para a compreensão de um pensamento coletivo. 


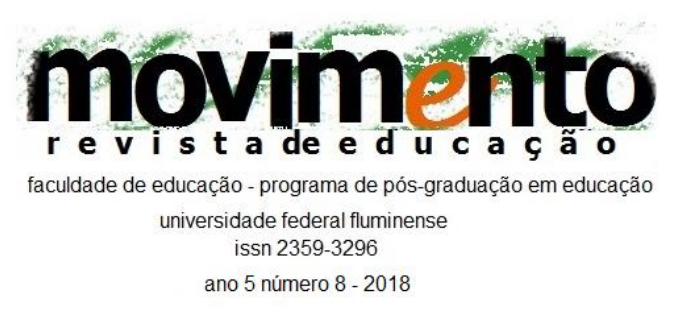

\section{Coleta de dados}

Foi escolhido um grupo social de professores de Ciências da Educação Básica (servidores da SEEDUC) atuantes no segundo segmento do ensino fundamental, do sexto ao nono ano, em escolas estaduais da Baixada Fluminense. Essa região metropolitana abrange 13 municípios e possui uma população numerosa e carente de serviços básicos. De acordo com o Índice de Desenvolvimento da Educação Básica (IDEB) de 2013, todos os 13 municípios da região estão abaixo da média do estado (5.2).

O grupo é composto por 15 professores ( 3 homens e 12 mulheres) com idade média de 40 anos (desvio padrão 7.15). Entre eles, 9 (60\%) fizeram especialização, 10 (67\%) lecionam apenas na rede estadual e 12 (80\%) declararam que exercem a profissão docente há mais de sete anos.

O tamanho da amostra de professores foi definido em função do caráter qualitativo desta pesquisa, centrada em entrevistas abertas. $O$ objetivo foi "explorar com profundidade o grupo em questão, pretendendo mais alcançar sua complexidade interna que fazer generalizações" (MINAYO, 2007, p.102).

Os depoimentos foram obtidos através de entrevistas abertas, realizadas no mês de abril de 2016. Todos os professores assinaram o Termo de Consentimento Livre e Esclarecido (TCLE) para a gravação de seus testemunhos. Foram seguidos os procedimentos éticos de pesquisa com seres humanos. O estudo insere-se em projeto avaliado e aprovado pelo Comitê de Ética e Pesquisa do Hospital Universitário da Universidade Federal do Rio de Janeiro (CEP-HUCCFUFRJ), com o protocolo CAAE 42628015.1.0000.5257. O projeto também foi submetido e aprovado pela SEEDUC, com o protocolo E/03/016/780/2015. 


\section{movimento \\ faculdade de educação - programa de pós-graduação em educação universidade federal fluminense \\ issn 2359-3296 \\ ano 5 número 8 - 2018}

As entrevistas ocorreram em uma sala reservada nas escolas onde os professores lecionam e em horários que não comprometessem suas aulas. Além disso, em momentos em que não houvesse a presença de interferentes. A questão indutora utilizada foi 'fale sobre o Currículo Mínimo de Ciências'. A ideia era permitir ao participante abordar livremente o tema pesquisado, de acordo com a metodologia proposta para entrevistas abertas (MINAYO, 2007).

Após a coleta de dados e a realização dos procedimentos metodológicos descritos, os textos das entrevistas foram reunidos em um discurso coletivo. A seguir, são apresentadas as ideias centrais extraídas das falas desses 15 professores.

\section{Resultados e Discussão: Os Discursos do Professor Coletivo}

Para explorar como os professores de Ciências receberam o CM e aquilo que pensam sobre essa proposta curricular, foi elaborado, com base nos depoimentos de 15 docentes, o Discurso do Sujeito Coletivo desse grupo. A Tabela 1 mostra as temáticas e as frequências (absoluta e relativa) de cada Ideia Central. Seguidamente, são apresentados os DSC e suas discussões.

\begin{tabular}{lcc}
\hline \multicolumn{1}{c}{ Ideias Centrais } & $\begin{array}{c}\text { Frequência } \\
\text { absoluta }\end{array}$ & $\begin{array}{c}\text { Frequência } \\
\text { relativa }(\mathrm{a})\end{array}$ \\
\hline Pontos positivos & 10 & $67 \%$ \\
Apresentação & 10 & $67 \%$ \\
Não bate com o livro! & 10 & $67 \%$ \\
Falta conteúdo & 12 & $80 \%$ \\
O Saerjinho & 14 & $93 \%$ \\
\hline \multicolumn{1}{c}{ Total de professores } & & 15
\end{tabular}

Tabela 1: Ideias Centrais presentes nos Discursos do Sujeito Coletivo (DSC) sobre 0 Currículo Mínimo de Ciências, dos professores de Ciências da rede pública estadual de ensino do Rio de Janeiro.

(a) as frequências relativas estão apresentadas apenas como referência figurativa. $O$ somatório das frequências ultrapassa o total de professores uma vez que o mesmo professor formulou em seu depoimento mais de uma ideia central. 


\section{movimento \\ faculdade de educação - programa de pós-graduação em educação universidade federal fluminense \\ issn 2359-3296 \\ ano 5 número 8 - 2018}

Os cinco discursos formulados a partir das ideias centrais encontradas nas entrevistas expressam as experiências de um sujeito coletivo e revela suas opiniões sobre a política curricular.

DSC1: Pontos positivos (67\%)

Não é só uma lista de conteúdos que tem que ser dados, são competências a serem trabalhadas. Eu acho que fica fácil, descompartimentaliza! E é pouca coisa, eu dou em duas semanas. No resto do tempo eu complemento. No sexto ano, ele é bem transversal, conversa com outras disciplinas. Você lida muito com o lúdico e tem que ensinar pro aluno que ele tem que conhecer o ambiente onde ele vive. Eu concordo com isso, porque eles trazem uma gama do dia a dia, é fácil pro aluno. No sexto e sétimo ano, não teve muito mistério, dá pra mesclar com o conteúdo do livro didático, tem as coisas que a gente veria mesmo, só não cobra mais as rochas. No oitavo, é fácil pra eles saberem que o coração faz o sangue circular e não todos os detalhes que eu entrava antigamente. Essa criançada quer ver o todo, é por ai. O nono é focado nas questões ecológicas, do meio ambiente, mas pra isso a gente tem que ter versatilidade pra introduzir coisas do cotidiano pra trabalhar com os alunos. Ele vem preenchendo as lacunas de ensino aprendizagem e já dá um suporte pro aluno lá na frente. Esse ano foi que a ficha caiu, que ele é realmente o mínimo que eu tenho que dar. $E$ foi a parte boa do currículo.

Os docentes dialogam sobre a percepção de um currículo voltado para o cotidiano, o qual destaca a visão do todo e a contextualização da aprendizagem. Tais observações são consonantes com as ponderações de Ventura e Freire (2017) em sua análise do CM de Ciências. Segundo o discurso dos professores de Ciências, essa é uma proposta que sugere olhar para o mundo holisticamente e que considera as limitações de estudar a complexidade sob o foco de uma única ciência.

O Currículo Mínimo de Ciências estabelece o cotidiano como objeto de investigação, segundo o DSC1. Além disso, é um currículo contextualizado. A extensão de conteúdos do $\mathrm{CM}$ é bem aceita como 0 essencial. Os conhecimentos básicos obrigatórios são trabalhados em poucas aulas e os 


\section{movimento \\ faculdade de educação - programa de pós-graduação em educação universidade federal fluminense \\ issn 2359-3296 \\ ano 5 número 8 - 2018}

professores dizem que complementam seu trabalho como desejam. Dessa forma, percebe-se que há liberdade para os docentes diversificarem seu trabalho em sala de aula.

Entretanto, antes de interpretarem o $\mathrm{CM}$, reconhecendo seus pontos positivos, e utilizarem-no em suas aulas, os professores foram apresentados à proposta em uma dinâmica aplicada pela rede. No DSC2, os docentes disseram como receberam o documento curricular implantado pela SEEDUC a partir da forma como foi apresentado.

DSC2: A apresentação (67\%)

Tudo na Seeduc chega às pressas. Muda o governo, muda a forma de ver o ensino. Ele foi assim, no supapo, buff! E foi no terceiro bimestre! A minha diretora falou que eu deveria seguir esse currículo. Mas quando eu me deparei com ele, foi um impacto: Caraca! É mínimo mesmo! Eu achei meio que inviável e como não tinha nenhuma cobrança eu simplesmente não usei. Não entendia aquilo, achei uma loucura. O que é isso? Eu acho que não houve uma conversa mais clara quando a proposta curricular foi implementada, pra mostrar como a gente deveria usar. Ele entrou engasgado pra gente! Não teve uma apresentação, uma preparação.

Segundo o DSC2, a chegada do Currículo Mínimo nas escolas foi uma ação inesperada para os professores de Ciências. Não houve, segundo o sujeito coletivo, sua participação na elaboração da proposta, nas discussões sobre ela e nem tampouco uma preparação dos docentes para desenvolvê-la.

Em 2011, o CM foi apresentado às escolas da rede, abrangendo algumas disciplinas. Nesse mesmo ano, a SEEDUC realizou chamadas públicas, em sua página eletrônica, selecionando professores da rede para participar da elaboração da CM para outras disciplinas, incluindo Ciências (RIO DE JANEIRO, $2011^{d}$ ). Isso ocorreu entre outubro de 2011 e junho de 2012 , quando se produziu um documento que chegou às escolas em agosto deste ano. 


\section{movimento \\ faculdade de educação - programa de pós-graduação em educação universidade federal fluminense \\ issn 2359-3296 \\ ano 5 número 8 - 2018}

As disciplinas incluídas no CM em 2012 não foram parte das avaliações realizadas pela rede estadual (SAERJ). Entretanto, o DSC2 reflete um professor que não foi preparado para desenvolver a proposta. Esse docente, na ausência de pressões institucionais naquele momento de implantação, simplesmente diz que não utilizou o novo currículo. Outros estudos baseados em entrevistas também posicionam o CM como alvo de polêmicas e de rejeições dentro de uma parcela significativa de professores da rede educacional fluminense (BARCELLOS, et al, 2013; CABRAL, 2014; DOS SANTOS, 2017).

O sujeito coletivo revela que teve surpresas e estranhezas com o documento curricular. $\mathrm{Na}$ busca de compreender esse sobressalto, outros núcleos centrais abordam o "inviável ... uma loucura!", na opinião dos professores de Ciências sobre o CM. O DSC3, apresentado a seguir, traz um dos pontos relacionados a essas inquietações.

DSC3 Não bate com o livro (67\%)

Tem uma coisa que me deixa muito irritada (o): ele não se adequa aos parâmetros curriculares nacionais, logo não bate às vezes com o livro. No sétimo ano não tem problema, tá bem dentro do currículo nacional mesmo. No segundo bimestre eu consegui usar o livro, porque fala de seres vivos, mas usa num bimestre e no outro não. Agora, no nono não tem como usar o livro com o aluno em momento nenhum. O currículo tem que ser em cima do livro. O conteúdo do livro didático é muito extenso, então eu trabalho todos os assuntos de forma corrida pra que tenham o conhecimento e um dia possam lembrar de que ouviram a palavra, o assunto. A gente tem que usar o livro e cada série tem seus assuntos. Quando termino o Currículo Mínimo eu pego o livrinho e ai a gente começa a estudar as coisas que estão lá. Eu quero seguir o livro, eu acho mais interessante.

Os docentes atentam para a incompatibilidade entre a proposta e o livro didático.

Segundo eles, o livro é a principal e, muitas vezes, a única referência nas salas de aula. No entanto, a SEEDUC oferece aos professores um suporte pedagógico para o desenvolvimento do currículo. Contudo, os professores que responderam 


\section{movimento \\ faculdade de educação - programa de pós-graduação em educação universidade federal fluminense \\ issn 2359-3296 \\ ano 5 número 8 - 2018}

o questionário de pesquisa observaram um uso muito restrito desse recurso virtual. Entre eles, apenas dois afirmaram ter acessado essas orientações pedagógicas pelo menos uma vez e somente um atestou consultar com regularidade o portal na elaboração de suas aulas.

Assim, embora haja um recurso oferecido pela SEEDUC, os professores atestam um desamparo quando buscam relacionar o CM ao livro didático. A proposta curricular não foi elaborada consonante às divisões já estabelecidas nos livros escolares, o que evidencia um problema perante a importância do livro didático na prática docente (APPLE, 2008; MUNAKATA; 2010). Marcelino et al (2013) entrevistaram professores da rede sobre o Currículo Mínimo e também ponderaram a dissincronia que havia entre a proposta e os livros e sinalizaram que os docentes "navegam sobre o livro didático buscando itens que coincidam com o conteúdo (...) e com isso o CM não é adotado pelos professores". Rodrigues e Frangella (2016) também fizeram observações parecidas em suas entrevistas com os docentes da SEEDUC e destacaram a "falta de aderência da proposta curricular com livros didáticos, que aparece com muita potência na fala dos docentes".

Apesar de haver uma política oficial do Estado, nesse discurso, configura-se a existência de um currículo não institucional enraizado nas escolas (APPLE, 2008). A expressão "O currículo tem que ser em cima do livro" sugere haver legitimidade no livro didático para os professores. Além disso, também sinaliza para um possível problema na aceitação do CM.

Por outra perspectiva, essa fala ultrapassa a noção de proteção discursiva ao refletir a constatação de outras pesquisas sobre o papel do livro didático enquanto dispositivo-chave na escolarização. Através do olhar de Munakata (2010, p.225), "aprender na escola é ler os textos que codificam os saberes. Estudar na escola é ler os livros didáticos. Lá escritura predomina”. 


\section{movimento \\ faculdade de educação - programa de pós-graduação em educação universidade federal fluminense \\ issn 2359-3296 \\ ano 5 número 8 - 2018}

As afirmações "tem que usar o livro" e "cada serie tem seus assuntos" no DSC3 aparecem como uma proteção das certezas que os docentes possuem diante de uma nova proposta curricular. Nessa perspectiva, o livro assume o caráter de 'currículo', ou seja, do 'documento' que define os conteúdos que devem ser 'ensinados'.

Esse DSC, somado aos anteriores, deixa a noção de que não se construiu junto aos professores a ideia de que o Currículo Mínimo é o caminho a ser experimentado pelas escolas como política oficial do estado. Possivelmente, essa consequência está relacionada à insuficiente discussão da proposta ou à dificuldade dos docentes para agirem diferente de suas práticas habituais.

Os discursos coletivos dos professores de Ciências caracterizam o CM como aquele que foi elaborado sem diálogos com a sua comunidade, mal apresentado e sem preparo para sua execução. Os materiais didáticos são incompatíveis com a proposta. Portanto, há dificuldades quanto a sua aceitação.

Apesar disso, os professores demonstraram receptividade com o texto do Currículo Mínimo e elogiaram a relação entre o tempo de aula e a quantidade de conteúdos obrigatórios no DSC1. Contudo, contraditoriamente, no DSC4, proferiram uma fala que o desaprova pela falta de conteúdos.

DSC 4: Falta conteúdo (80\%)

Ele tem conteúdos bem pequenos. Eu acho pouco pra um bimestre e muitas vezes não é o conteúdo que nós estávamos acostumados a trabalhar. A grande graça de ser professor (a) é tentar dar a matéria toda, o livro todo. Com esse currículo fica faltando coisa, me dá essa agonia. Eu não vou dar tudo? O livro é extenso! (...) Não sei se foi como eu aprendi, mas, com ele, parece que eu não dei aula. Eu assumo, eu sou conteudista. Eu sigo a ordem do Currículo Mínimo, mas quando sobra tempo eu pego o conteúdo tradicional do livro. É uma coisa que já vinha 


\section{movimento \\ faculdade de educação - programa de pós-graduação em educação universidade federal fluminense \\ issn 2359-3296 \\ ano 5 número 8 - 2018}

determinada e o Currículo Mínimo muda a ordem daquilo que tá no nosso sangue. Essa viagem eu faço se der tempo, eu aplico o conteúdo normal. Eu sei o que é necessário em cada série, tudo na medida certa. Esse currículo tira a minha autonomia, eu não ficava preso numa coisa muito pequena, pra mim, essa é a parte ruim dele. Tinha que voltar ao currículo anterior, porque falta conteúdo do livro didático.

A contraposição quanto à adequação da quantidade de conteúdos do $\mathrm{CM}$, caracterizada nos DSC 1 e 4, é clarificada pelo referencial do livro didático, que aparece como conflitos identitários em outros DSC dos docentes. Ao mesmo tempo em que o discurso mostra o $\mathrm{CM}$ como ajustado à totalidade das aulas com sobra de tempo para diversificação, paradoxalmente, caracteriza-o como cerceador da autonomia pedagógica dos professores.

No entanto, o discurso dos docentes defende uma autonomia vinculada aos livros didáticos, professados como recipientes de todo o conteúdo. As exposições dos docentes sugerem que a proposta os incomoda, porque existe algo mais forte que "é uma coisa que já vinha determinada (...) que tá no nosso sangue (...) que é (...) o conteúdo normal". Com essa posição, o DSC4 revela que esses percalços estão mais relacionados à perda da autonomia e à imposição para fazer uma prática curricular diferente da estabelecida do que aos "conteúdos pequenos".

Na discussão dos DSC anteriores, mencionou-se a importância da participação e da preparação dos professores para a implantação de reformas educacionais. No entanto, no DSC4, observa-se um ponto relevante que deve ser discutido não apenas com professores, mas também com a sociedade. Nele, existe um entendimento de que o professor tem que 'dar tudo', o conteúdo todo, o livro todo. O "ter que dar todo o conteúdo" assume uma perspectiva próxima do modelo de educação bancária descrito por Paulo Freire (1997). Nesse modelo, os docentes transmitem e depositam os saberes em seus alunos. A centralidade 


\section{movimento \\ faculdade de educação - programa de pós-graduação em educação universidade federal fluminense \\ issn 2359-3296 \\ ano 5 número 8 - 2018}

da escolarização é descrita no discurso como ter que dar a matéria e o foco na aprendizagem dos alunos é marginalizado.

A noção de que todo o conhecimento é apreciável e tangível é questionável perante as mudanças tecnológicas ocorridas no século $X X$. O crescimento exponencial do conhecimento e as tecnologias disponíveis hoje fornecem aos estudantes a possibilidade de acessar através de seus polegares todo o conhecimento disponível na palma de suas mãos. Os jovens dominam e têm acesso às tecnologias, diferente das gerações anteriores, as quais recorriam apenas aos livros e às enciclopédias. Acessam-nas em qualquer, a qualquer momento, e compartilham-nas com pessoas de qualquer lugar do planeta com seus polegares (SERRES, 2013).

A nossa estrutura escolar centrada em certezas vive uma crise perante um mundo cada vez mais inseguro e plural (FLECHA. TORTAJADA, 2000; SIBILIA). Nesse novo mundo, é fundamental repensar a 'escola' que desejamos para nossos alunos, os quais têm concepções diferentes das nossas quanto aos saberes, à aprendizagem e à informação. Ao fim, quanto ao que é significativo.

O aforisma que situa alunos do século XXI em escolas do século XIX, cujos professores são do século XX, faz-se presente nas justificativas para os dilemas que a escola pública contemporânea deve enfrentar. Além disso, as questões relativas à valorização da profissão docente - incluindo a remuneração - e às necessidades de investimentos em formação e na qualidade do ambiente de trabalho do professor são discutidas por muitos autores (NÓVOA, 1992; SCHEIBE, 2010; BRZEZINSKI, 2013).

Nesse contexto, anunciado no discurso dos professores, a SEEDUC induz as escolas a realizarem a proposta curricular através de sua avaliação externa, o 


\title{
movimento \\ faculdade de educação - programa de pós-graduação em educação universidade federal fluminense \\ issn 2359-3296 \\ ano 5 número 8 - 2018
}

SAERJ. Essa é uma avaliação diagnóstica, que traz dados estatísticos para a Secretaria de Educação.

Porém, o SAERJ é baseado no documento curricular e associado a metas de pontuação e de bonificação de docentes e de estudantes. Sua importância na implantação do CM é abordada no DSC5, o qual explora essa estratégia de regulação que direciona a internalização da política nas escolas.

DSC5 O Saerjinho (93\%)

\begin{abstract}
No ano seguinte a matéria de Ciências passou a ser avaliada no Saerjinho. Ai, eles te prendem nisso, porque é cobrado numa prova, no sexto e no nono ano. Isso me força a segui-lo, pois meus alunos tem que ir bem na prova. Antes disso eu usava o livro, só com essa prova que eu passei a tê-lo como diretriz, como meta, né. Eu trabalho o conteúdo do livro didático, até três semanas antes do saerjinho, aí eu dou ele porque a escola diz que tem que dar. A partir do momento em que tem uma avaliação externa eu começo a preparar para o Saerjinho, até porque isso vai contar como nota pra escola e vão comparar as turmas. Eu fico com medo! Essas avaliações são uma forma de fiscalizar o nosso trabalho. Isso engessou a gente! Quando não tinha saerjinho no sexto ano eu não usava. E o estado promete tablet aos melhores. Eu não vou prejudicar o meu aluno, porque ele também vai me questionar se eu não der isso. Uma colega foi encostada na parede pelos alunos porque não caiu nada do que ela tinha dado. No ano seguinte ela começou a usar só o Currículo Mínimo e é o que todos fazem. No sétimo ano os alunos não fazem o Saerj e eu tenho mais liberdade e não uso, eu só trabalho o Currículo Nacional, No nono eu tiro uma semana só pra trabalhar só as questões do Saerjinho depois dos conteúdos normais. É behaviorismo, mesmo. Eu deixo pra mais perto, pra ficar mais fresco. Eu trabalho o Currículo Mínimo por obrigação, porque eu não quero prejudicar a escola.
\end{abstract}

Segundo o DSC5, os professores não foram convencidos de que a proposta curricular é um ponto importante das mudanças em implantação pelo governo. $\mathrm{Na}$ fala dos docentes, o CM só é trabalhado em suas aulas às vésperas das avaliações realizadas pela SEEDUC. Nesse enunciado, observa-se que a ausência da pressão da avaliação em algumas séries deixa o professor à vontade para usar ou não a proposta curricular. 


\section{movimento \\ faculdade de educação - programa de pós-graduação em educação universidade federal fluminense \\ issn 2359-3296 \\ ano 5 número 8 - 2018}

Dessa maneira, essas avaliações da rede funcionam como uma pressão institucional sobre os docentes. Uma coação que os leva a desenvolver o currículo, apesar das resistências. Ao investigarem a influencia do SAERJ na prática docente, outros autores também destacaram o papel da avaliação externa como uma forte pressão institucional na indução do uso do Currículo Mínimo pelos professores (CERQUEIRA et. al. 2016, RODRIGUES, COSTA; 2017; DOS SANTOS 2017). Bonamino e Sousa (2012, p. 386) nos alertam sobre o uso das avaliações externas nas políticas educacionais, pois existe o risco de a escola passar a "preparar seus alunos para os testes, levando a um estreitamento do currículo escolar". Além de espelhar "as avaliações da aprendizagem na avaliação em larga escala".

A insatisfação com as pressões dessa avaliação externa e sua interferência na aprendizagem escolar foram uma das principais manifestações dos docentes na greve realizada em 2016. Esse movimento, associado à grave crise financeira enfrentada pelo estado, levou a SEEDUC a suspender o SAERJ e reelaborar um modelo de avaliação em larga escala com maior aceitação pelos docentes (CARDOZO, 2016; FOURNIER, 2017).

É de fundamental importância, em uma política educacional que visa às transformações e às melhorias de qualidade, que se busque diagnosticar os problemas presentes nas escolas através de ferramentas como as avaliações. Contudo, se o caráter diagnóstico dessa ferramenta é desviado a uma política de busca de resultados, haverá distorções em seus objetivos e em suas consequências como as apresentadas no DSC5.

O ultimo DSC manifesta que a solução encontrada pelo sujeito coletivo, que representa 93\% dos professores entrevistados, é trabalhar o CM para as avaliações como um treinamento em sua véspera. Essa estratégia acerta três alvos de uma só vez: a obrigatoriedade de seguir a proposta curricular, a 


\section{movimento \\ faculdade de educação - programa de pós-graduação em educação universidade federal fluminense \\ issn 2359-3296 \\ ano 5 número 8 - 2018}

preparação para a avaliação e a manutenção das práticas pedagógicas já estabelecidas.

\section{Considerações finais}

O conteúdo das Representações Sociais Discursivas indica que os professores participantes desse estudo vivem em um momento de ajustes e de apropriação com a política educacional. Através de um sujeito coletivo, descrevem uma reforma curricular apresentada sem diálogos, imposta por pressões meritocráticas e de avaliações, que os impulsionam a realizá-la. Ao tentar colocar o CM em ação, encontram conflitos e dificuldades para por em prática uma proposta que posiciona o aluno como foco da aprendizagem. Os professores dizem que não se sentem preparados para esse modelo educacional.

Segundo seus discursos, as suas práticas pedagógicas são centradas nos livros, cujos conteúdos são pré-estabelecidos com o que deve ser ensinado em cada série. $O$ texto curricular baseado em habilidades conflita com a prática dos professores e o uso dos livros didáticos.

$\mathrm{Na}$ opinião dos docentes, falta conteúdo no currículo e esse não ocupa a totalidade das suas aulas. Entretanto, a sua autonomia pedagógica parece estar centrada nos livros escolares. Apesar disso, o sujeito coletivo elogia o CM como atual e contextualizado.

As dificuldades apresentadas pelos professores quanto à falta de preparo para efetivar a proposta em suas aulas são confrontadas com o dever profissional de aderir à reforma. Existe uma política institucional que obriga os docentes a fazêla. Ela é compulsoria, com base em uma avaliação externa e utiliza-se de bonificação para que haja adesão ao programa. Contudo, os resultados 


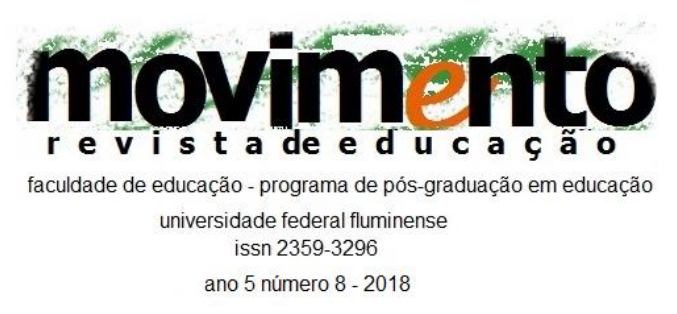

apresentados indicam que a proposta da SEEDUC não se enraizou no chão das escolas como prática dos professores. O Currículo Mínimo só é trabalhado para e por causa das avaliações.

Em uma reforma curricular, com transformações estruturais que modificam radicalmente as práticas educativas, as resistências, os conflitos e as dificuldades possivelmente se farão presentes. Os professores são exigidos a desenvolver propostas que requerem um remodelar pedagógico de si, comprimidos por metas a serem alcançadas.

Nessa ótica, a animação do currículo só é possível pelas mãos dos docentes em sua sala de aula. Os professores têm um papel ativo em seu desenvolvimento quando interpretam o currículo na singularidade de sua realidade e exercitam a sua capacidade criativa, fazendo a proposta chegar aos alunos (PACHECO, 1995, p.107).

O objetivo principal desse estudo foi apresentar como esse grupo de professores enxerga a implantação do CM de ciências pela rede estadual do Rio de Janeiro. Nesse intuito, o sujeito coletivo dos professores diz ter dificuldades em lidar com o Currículo Mínimo e revela percalços na forma de implantação.

Entrar na proposta curricular para esse sujeito coletivo foi um caminho sem escolhas. Com isso, o CM é trabalhado para atender às avaliações, mas, mesmo assim, as práticas docentes permanecem inalteradas. A tentativa dos elaboradores da política de torná-la eficaz, condicionando o currículo a uma política de accountability, com pressões institucionais, esbarra na discricionariedade daqueles que fazem as políticas públicas na rua (ARRETCHE; 2001). No caso do Currículo Mínimo de Ciências, há uma grande distância entre os objetivos e o desenho concebidos originalmente para 


\section{movimento \\ faculdade de educação - programa de pós-graduação em educação universidade federal fluminense \\ issn 2359-3296 \\ ano 5 número 8 - 2018}

desenvolver habilidades e competências e a tradução de tais concepções pelos professores entrevistados

Baseado nos discursos do sujeito coletivo analisados, enfatizamos que transformações factuais na educação requerem sólidos investimentos na formação e nas condições de trabalho dos professores. Além disso, diálogos, debates e ampla participação são extremamente necessários para a compreensão e para o engajamento dos docentes na proposta que o estado deseja implantar.

As discussões abordadas em pesquisas sobre a implementação de políticas educacionais através do ponto de vista de seus atores são fundamentais para reflexões acerca de sua efetividade e de sua aceitação. Não basta haver uma política elaborada. Ela não ganhará vida espontaneamente nem se desenvolverá nas escolas do mesmo modo como idealizada por aqueles que elaboram essas políticas (LIPSKY; 1980).

Haverá falhas, ressignificações e problemas. Stephen Ball (1994) afirma que é fundamental diagnosticar os desequilíbrios e as dificuldades gerados pela política em questão. Essas análises trazem indicadores para a elaboração de estratégias que tragam a possibilidade de avanços nos propósitos pretendidos pelas políticas em questão.

No caso desses professores de Ciências da rede estadual pública de ensino do Rio de Janeiro, é fundamental desenvolver meios que deixem mais claros os objetivos da política. Além disso, que haja uma adequação entre o material pedagógico adotado e o CM. Deve-se implementar estratégias para capacitar os professores a lidar com a estrutura contemporânea dos currículos, a qual é subjetiva e baseada em habilidades e competências. A formação e a profissão 


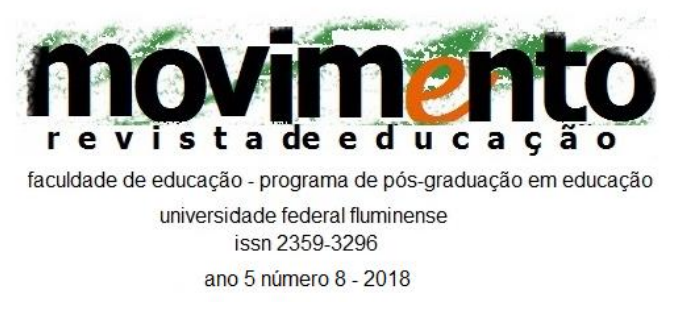

docente devem ser priorizadas para melhorar a qualidade da educação (MELLO; 2000; GATTI; 2016).

A importância das avaliações em larga escala como um indicador de fragilidades e de caminhos em busca de avanços no campo educacional é inquestionável. Contudo, seus usos devem encerrar-se nesses pontos. Não devem estar associadas à classificação, à meritocracia e às premiações. Politicas educacionais centralizadas em avaliações afetam a prática docente, os objetivos dos currículos e da aprendizagem escolar (FREITAS; 2009; SOUSA, ARCAS; 2010).

Muito além disso, é fundamental que os professores sejam clarificados quanto à política que se deseja implantar. A governabilidade de uma política educacional é dependente da parceria entre o estado e aqueles que estão com giz em suas mãos (TENDLER; 1997; LOTTA; 2012).

Os estudos sobre as políticas educacionais são de fundamental importância, especialmente no presente, quando se aproxima a implantação da Base Nacional Comum Curricular. É preciso que essas políticas sejam consolidadas com longevidade, com objetivos claros, pedagogicamente definidos e didaticamente diversificados, os quais sejam plenamente esclarecidos e justificados para aqueles que farão sua efetivação. Dessa maneira, somente com o engajamento e a participação dos professores, será possível consolidar um projeto educacional eficaz.

\section{Referências Bibliográficas}

ABRIC, J. Prácticas sociales y representaciones, Las representaciones sociales: aspectos teóricos. Pratiques sociales et représentations. 2003. p.1-32. 


\section{movimento \\ faculdade de educação - programa de pós-graduação em educação universidade federal fluminense \\ issn 2359-3296 \\ ano 5 número 8 - 2018}

APPLE, M. Currículo, poder e lutas educacionais: com a palavra, os subalternos. Artmed, 2008. 295 p.

ARRETCHE, Marta. Uma contribuição para fazermos avaliações menos ingênuas. In: MOREIRA, M; CARVALHO, M (Org.). Tendências e perspectivas na avaliação de políticas e programas sociais. São Paulo: IEE/PUC SP, 2001.

ASSMANN, H. Reencantar a educação: rumo à sociedade aprendente.Vozes; 1999.

BALL, S. Educational reform: a critical and post-structural approach.

Buckingham: Open University Press, 1994. 164 p.

BALL, S. Reformar escolas/reformar professores e os terrores da performatividade. Revista Portuguesa de Educação, v. 15, n. 2, 2002, p. 3-23.

BARCELLOS, M et al. Currículo mínimo e avaliação no estado do Rio de Janeiro: Uma questão de competência ou conteúdo?. 2013 Anais do IX Encontro Nacional de Pesquisa em Educação em Ciências - IX ENPEC; 2013.

BARRETTO, E et al. Políticas de currículo e avaliação e políticas docentes. Cadernos de pesquisa, v. 42, n. 147, p. 738-753, 2012.

BOURDIEU, Pierre. Structures, habitus, power: Basis for a theory of symbolic power. Culture/power/history: A reader in contemporary social theory, 1994. p. 155-199.

BRASIL, Instituto Nacional de Estudos E Pesquisas Educacionais Anísio Teixeira- INEP; Índice de desenvolvimento da educação básica; 2010

BRASIL; Instituto Nacional de Estudos E Pesquisas Educacionais Anísio Teixeira- INEP. Sinopses Estatísticas da Educação Básica, 2014.

BROOKE, N. et. al.. A avaliação externa como instrumento da gestão educacional nos estados. Estudos \& Pesquisas Educacionais, São Paulo, v. 2, p. 17-79, 2011.

BRZEZINSKI, I. Formação e Valorização dos Profissionais da Educação e o Plano Nacional de Educação (2012-2?). Educativa, v. 16, n. 1, 2013.p.1-17.

CABRAL, M. O Currículo Mínimo, o Ensino de História e o Sistema Estadual de Avaliação no Estado do Rio de Janeiro: reflexões sobre os processos de ensino e aprendizagem na escola básica. Revista História Hoje, v. 4, n. 8, p. 328-347, 2016. 


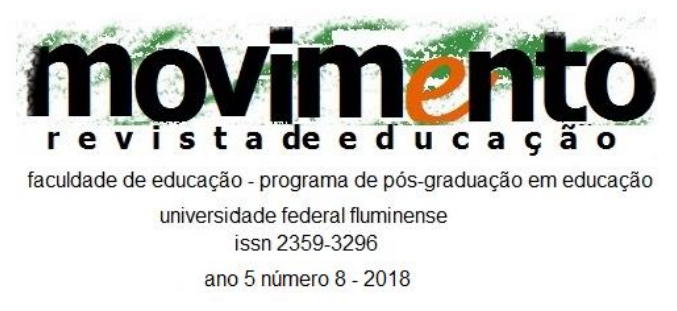

CANÁRIO, R. A Escola tem Futuro?. Artmed Editora, 2009. 162p.

CARDOZO, A. A luta educa e transforma: a possibilidade de reconstrução da cidade através da greve de 2016 dos professores do estado do rio de janeiro. ANAIS - NUGEA-UFJF; 2016.

CERDEIRA, D; ALMEIDA, A. Os efeitos da política de avaliação e responsabilização educacional na rede pública do Rio de Janeiro. XVI ENDIPE - Encontro Nacional de Didática e Práticas de Ensino, Anais, Julho, 2013.

CERQUEIRA, L. et. al. Política de Avaliação do Estado do Rio de Janeiro: repercussões na gestão escolar e no currículo. Práxis Educativa, v. 11, n. 3, p. 676-692, 2017.

CHIRINÉA, A, BRANDÃO, C. O IDEB como política de regulação do estado e legitimação de qualidade. Ensaio: Avaliação e Políticas Públicas em Educação, v. 23, n. 87,2015 . p. $461-484$.

DOS SANTOS, C. As práticas docentes e o Currículo de Geografia no Estado do Rio de Janeiro. Práxis Educativa, v. 12, n. 1, p. 83-98, 2017.

FALVO, J; AMARAL, A. Brasil no PISA 2015: análise pedagógica e indicadores sociais, educacionais e econômicos. 2017.

FLECHA, R; TORTAJADA, I. Desafios e saídas educativas na entrada do século.in: Iberon, F.A educação no século XXI: os desafios imediatos. Porto Alegre: Artmed, 2000.p.20-37.

FOUCAULT, M. A Ordem do discurso. Edições Loyola, 2004. 79 p.

FOURNIER, C. A política educacional de centralização, responsabilização e avaliação no estado do Rio de Janeiro: um estudo de caso sobre os desafios e dificuldades da atuação dos AAGES nas escolas da regional metropolitana III. UFJF. Tese. 2017.

FREIRE, P. Educação" bancária" e educação libertadora. Introdução à psicologia escolar, v. 3, p. 61-78, 1997.

FREITAS, L. Políticas de avaliação no Estado de São Paulo: o controle do professor como ocultação do descaso. Revista Educação \& Cidadania. Campinas (SP), v. 8, n. 01, p. 59-66, 2009. 


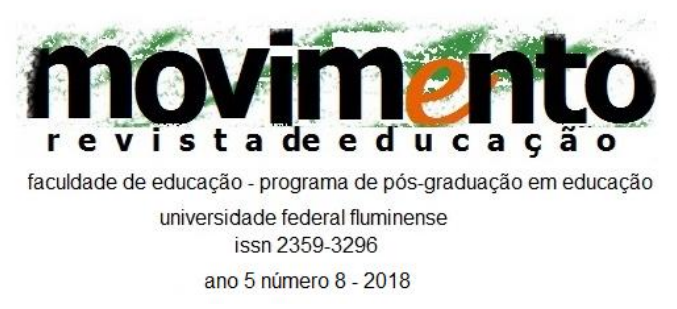

GATTI, A. Formação de professores: condições e problemas atuais. REVISTA INTERNACIONAL DE FORMAÇÃO DE PROFESSORES, v. 1, n. 2, 2016.

GUIMARÃES, M. A consolidação da política de avaliação da educação básica no Brasil. Revista Meta: Avaliação, v. 1, n. 3, 2009, p. 271-296.

HAMILTON, D. O revivescimento da aprendizagem. Educação e Sociedade 78 (2002): p. 187-198

JODELET, D.1985. La representación social: Fenómenos, concepto y teoría. In: Psicologia Social (S. Moscovici, org.), Barcelona: Paídos, p. 469-494.

JODELET, D. Interconnections between social representations and intervention. Social Representations in the 'Social Arena'. London: Routledge, 2015. p. 77-88.

JORGE, L. Inovação curricular: além da mudança de conteúdos. Piracicaba: Editora Unimep, 1996. 79 p.

LEFEVRE, F; et. al.. Discourse of the collective subject, complexity and selforganization. Ciencia \& saude coletiva, v. 14, n. 4, p. 1193-1204, 2009.

LEFEVRE, F; LEFEVRE, A. O sujeito coletivo que fala o que fala. InterfaceComunic, Saúde, Educ, v. 10, n. 20, 2006; p. 517-524.

LEFEVRE, F; LEFEVRE, A. Discurso do Sujeito Coletivo, complexidade e autoorganização. Ciências e Saúde Coletiva. 2009; 14(4): p. 1193-120.

LEFEVRE, F; LEFEVRE, A. Discurso do sujeito coletivo: representações sociais e intervenções comunicativas. Texto \& Contexto Enfermagem, v. 23, n. 2, 2014 p. 502-507.

LIBÂNEO, J. Internacionalização das políticas educacionais e políticas para a escola: elementos para uma análise pedagógico-política de orientações curriculares para ensino fundamental. Encontro Nacional de Didática e Práticas de Ensino, XVI, 2012, Campinas. Anais eletrônicos. Campinas: 2012.

LIPSKY, M. Street-level bureaucracy: dilemas of the individual in public services. NY: Russell Sage Foundation, 1980.

LOPES;A Políticas curriculares: continuidade ou mudança de rumos?Brasileira de Educação. n.26 Rio de Janeiro maio/ago. 2004; p.109-117. 


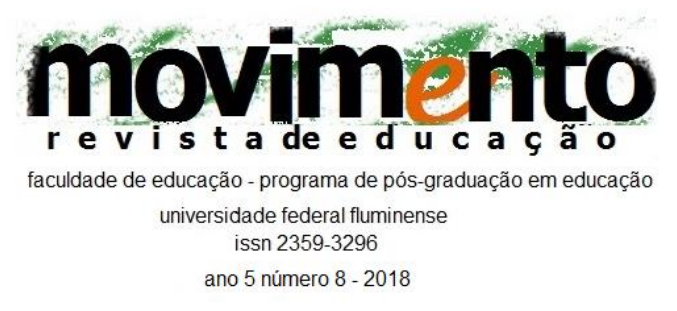

LOTTA, G. O papel das burocracias do nível da rua na implementação de políticas públicas: entre o controle e a discricionariedade. In: FARIA, C. A (org). Implementação de Políticas Públicas. Teoria e Prática. Editora PUCMINAS, Belo Horizonte, 2012.

MARCELINO, V; LINHARES, M; OLIVEIRA, F. O Ensino de química praticado em escolas estaduais de um município do estado do Rio de Janeiro/Brasil pela ótica de seus professores. Enseñanza de las ciencias: revista de investigación y experiencias didácticas, n. Extra, p. 1023-1027, 2013.

MAZZOTTI, A. Representações sociais: aspectos teóricos e aplicações à educação. Em aberto, v. 14, n. 61, 2008.

MELLO, G. Formação inicial de professores para a educação básica: uma (re) visão radical. São Paulo em perspectiva, v. 14, n. 1, p. 98-110, 2000.

MINAYO, A. Pesquisa Social. Teoria, método e criatividade. ed. Petrópolis: Vozes, 2007; $80 \mathrm{p}$.

MOSCOVICI, S. Notes towards a description of social representations. European journal of social psychology, v. 18, n. 3, 1988; p. 211-250.

MUNAKATA, K. Livro, livro didático e forma escolar. Convergências e tensões no campo da formação e do trabalho docente. Belo Horizonte: Autêntica, v. 1, 2010, p. 219-240.

NASCIMENTO, T. A educação, o ensino de história e o currículo mínimo do estado do Rio de Janeiro: currículo escrito, em ação e formação de professores. História \& Ensino, v. 19, n. 2, p. 87-114, 2014.

NÓVOA, A. Formação de professores e profissão docente. Os professores e a sua formação, Lisboa, Ed. Dom Quixote. 1992.p;15-33.

PACHECO, J. Currículo: teoria e práxis. Porto: Porto Editora. 1995. 280 p.

PAPERT, S. A máquina das crianças: repensando a escola na era da informática. 2008. $210 \mathrm{p}$.

PERRENOUD, P. Desenvolver competências ou ensinar saberes?: A escola que prepara para a vida. Penso Editora, 2013. 223p.

REY, B. As competências transversais em questão. Artmed, 2002. 232 p. 


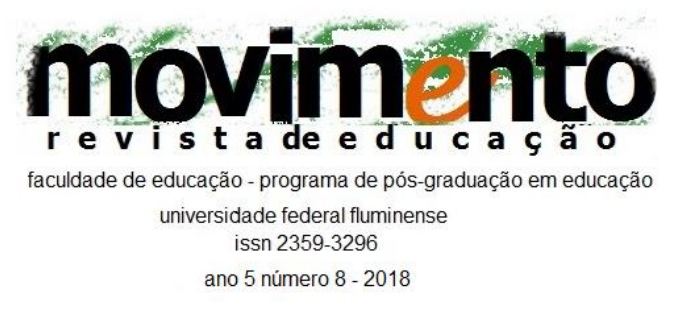

RIBEIRO, S. A educação e a inserção do Brasil na modernidade. Cadernos de Pesquisa, n. 84, p. 63-82, 2013.

RIO DE JANEIRO, Currículo Mínimo de Ciências e Biologia, 2012, disponível em http://www.ri.gov.br/web/seeduc/exibeconteudo?article-id=759820, acessado em 11/02/2014.

RIO DE JANEIRO, Educação lança Currículo Mínimo nas unidades de ensino, 2011c disponível em: http://www.ri.gov.br/web/imprensa/exibeconteudo?articleid=353541. Acesso em 14/02/2014.

RIO DE JANEIRO, Planejamento estratégico da SEEDUC, 2011 b disponível em: http://www.ri.gov.br/web/seeduc/exibeconteudo?article-id=1687124, acesso em 12/02/2014.

RIO DE JANEIRO, Professores discutem o Currículo Mínimo na rede estadual

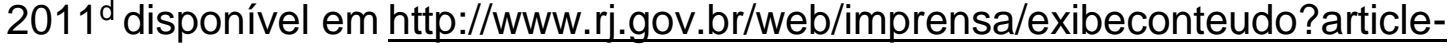
id=649850, acesso em 14/02/2014.

RIO DE JANEIRO, Secretaria de Estado de Educação, Melhores alunos da rede são premiados com notebooks, 2011ª, Disponível em:

http://www.ri.gov.br/web/seeduc/exibeconteudo?article-id=623022, acesso em $12 / 02 / 2014$.

RODRIGUES, P. FRANGELLA R. O CURRÍCULO MÍNIMO DA SEEDUC-RJ: A PRODUÇÃO DE POLITICAS CURRICULARES E PERSPECTIVAS PARA PROFESSORES DE GEOGRAFIA. Anais. III Congresso Nacional de Educação; 2016.

RODRIGUES, P; COSTA, H. A produção de políticas de currículo para geografia no estado do Rio de Janeiro: sentidos docentes para além do mínimo. Periferia, v. 8, n. 2, p. 108-126, 2017.

SACRISTÁN, J. O currículo: uma reflexão sobre a prática. Porto Alegre: ArtMed, 2000; $352 \mathrm{p}$.

SCHEIBE, L. Valorização e formação dos professores para a educação básica: questões desafiadoras para um novo plano nacional de educação. Educ. Soc, v. 31, n. 112, 2010, p. 981-1000.

SEGATTO, C; ABRUCIO, F. A gestão por resultados na educação em quatro estados brasileiros. Revista do Serviço Público, v. 68, n. 1, p. 85-106, 2017

SERRES, M. Polegarzinha. Rio de Janeiro: Bertrand Brasil, 2013. 96p; $21 \mathrm{~cm}$. 


\section{movimento \\ faculdade de educação - programa de pós-graduação em educação universidade federal fluminense \\ issn 2359-3296 \\ ano 5 número 8 - 2018}

SIBILIA, P. Redes ou paredes: a escola em tempos de dispersão. Rio de Janeiro: Contraponto, 2012. 224p.

SOUSA, S; ARCAS, P. Implicações da avaliação em larga escala no currículo: revelações de escolas estaduais de São Paulo. Educação: Teoria e prática, v. 20, n. 35, p. 181, 2010.

SOUSA, S; Concepções de qualidade da educação básica forjadas por meio de avaliações em larga escala, Avaliação, Campinas; Sorocaba, SP, v. 19, n. 2, , 2014; p. 407-420.

TEIXEIRA, M. Conflito social pela educação de qualidade. uma reflexão sobre os sistemas de avaliação educacional. InterSciencePlace, v. 10, n. 2, 2015. p. 118-134.

TENDLER, J. Good government in the tropics. Johns Hopkins University Press, 1997.

VALA, Jorge. As representações sociais no quadro dos paradigmas e metáforas da psicologia social. Análise Social, v. 28, n. 123/124-1993; p. 887919.

VELLOSO, A. Representações Sociais e a construção da Identidade Profissional de Professor, 2009. Tese de Doutorado. PGED-Instituto de Bioquímica Médica, Universidade Federal do Rio de Janeiro.

VENTURA, G; FREIRE, L. As finalidades da educação em ciências no currículo mínimo de ciências/biologia: uma análise discursiva da rede estadual do Rio de Janeiro. Alexandria: Revista de Educação em Ciência e Tecnologia, v. 10, n. 1, p. 305-327.

\section{SOBRE OS AUTORES}

DIEGO MOTA é professor do Colégio Pedro II. Mestre em Biologia Geral pela Universidade Federal do Rio de Janeiro (UFRJ). Pesquisador do Laboratório em Formação (UFRJ).

E-mail: diegoomota@gmail.com 


\section{movimento \\ faculdade de educação - programa de pós-graduação em educação universidade federal fluminense \\ issn 2359-3296 \\ ano 5 número 8 - 2018}

DENISE ROCHA CORREA LANNES é professora Associada do Instituto de Bioquímica Médica da Universidade Federal do Rio de Janeiro (UFRJ). Doutora em Educação Gestão e Difusão em Biociências pela mesma instituição.

E-mail: dimolay@gmail.com

Recebido em: 30.01.2018

Aceito em: 29.05.2018 